\title{
Personality styles and defense mechanisms in a community sample of adolescents: An exploratory study
}

Inês Rachão, MSc

Rui C. Campos, PhD

This study aimed to test if the preference for using certain types of defense mechanisms, according to Ihilevich and Gleser's (1969, 1986) perspective, is associated with personality styles, proposed by Millon (1993), and also, aimed to test if both constructs give a contribution to the identification of global types of psychological functioning in adolescents. Eight hundred and thirty adolescents, ranging in age from 14 to 19 years $(M=16.64, S D=1.9)$ participated in the study. The Portuguese versions of the Defense Mechanisms Inventory for Adolescents and the Millon Adolescents Clinical Inventory were administered. Multiple linear regression analysis and principal component analysis were computed. Results demonstrate an association between defense mechanisms and personality styles and both constructs contribute to the identification of two types of psychological functioning in adolescents: an internalizing type and an externalizing type. (Bulletin of the Menninger Clinic, 79[1], 14-40)

Understanding personality and identifying its basic components has been the main goal of many authors throughout the history of psychology (e.g., Eysenck, 1950; Fruyt, Bolle, McCrae, Terracciano, \& Costa, 2009; Jung 1921/1958). Personality can be considered as a complex pattern of stable psychological

This article is based in part on the first author's master thesis in clinical psychology under the supervision of the second author. Grateful thanks are extended to all of the participants in this study. Inês Rachão is a Master in Clinical Psychology in the Department of Psychology, University of Évora, Portugal. Rui C. Campos is an Assistant Professor in the Department of Psychology, and is a member of the Research Center in Education and Psychology (CIEP), University of Évora, Portugal.

Correspondence may be sent to Rui C. Campos, Department of Psychology, University of Évora, Apartado 94, Évora, Portugal 7002-554; e-mail: rcampos@uevora.pt (Copyright (@) 2015 The Menninger Foundation) 